\title{
EDUCAÇÃO TERAPÊUTICA: TRATAMENTO DO TRANSTORNO DO ESPECTRO AUTISTA (TEA) A PARTIR DA INCLUSÃO ESCOLAR ${ }^{1}$
}

\section{THERAPEUTIC EDUCATION: TREATMENT OF AUTISTIC SPECTRUM DISORDER (ASD) FROM SCHOOL INCLUSION}

Rafael Amboni Dal Moro ${ }^{2}$

Gustavo Silveira ${ }^{3}$

\section{RESUMO}

A Educação Terapêutica tem sido uma estratégia cada vez mais utilizada na última década, visando a inclusão de crianças com necessidades especiais dentro do ensino regular. Tais estratégias vêm sendo desenvolvidas por Kupfer (1997; 2000; 2010) e Kupfer et al. (2017; 2018) há aproximadamente vinte anos. A referente pesquisa teve por objetivo indicar os recursos da Educação Terapêutica para o tratamento do TEA através da inclusão escolar; apontando também alguns dos seus fundamentos teóricos. Quanto à metodologia, tratou-se de uma revisão de literatura específica, de abordagem qualitativa e de natureza exploratória. A Educação Terapêutica procura potencializar as possibilidades da criança, muitas vezes restritas devido à sua condição psíquica. Nesse âmbito, a Educação Terapêutica pode ser definida como um conjunto de práticas que aliam educação e tratamento para crianças deficientes e/ou com graves distúrbios de desenvolvimento, comprometidas em sua constituição subjetiva. Observa-se que nos últimos anos vários trabalhos vêm mostrando a eficácia que uma formação de educadores e educadoras voltada aos princípios da educação terapêutica contribui sobremaneira para o tratamento e redução de sinais e sintomas atinentes ao transtorno no espectro autista.

Palavras-chave: psicologia. Educação Terapêutica. Autismo. Inclusão. Escolas.

1 O presente trabalho foi realizado com apoio do Programa de bolsas Universitárias do Estado de Santa Catarina - UNIEDU”. Juntamente com a Universidade do Contestado - Campus Rio Negrinho.

2 Mestre em Filosofia pela Pontifícia Universidade Católica do Paraná. Graduado em Psicologia pela Pontifícia Universidade Católica do Paraná. Graduado em Filosofia pela FAE Centro Universitário. Curitiba-PR, Brasil. E-mail: rafaeladmoro@outlook.com

${ }^{3}$ Graduando em Psicologia pela Universidade do Contestado - Campus Rio Negrinho. São Bento do Sul-SC, Brasil. E-mail: gusilveira29@gmail.com 


\section{ABSTRACT}

Therapeutic Education has been a strategy increasingly used in the last decade, aiming at the inclusion of children with special needs in regular education. Such strategies have been developed by Kupfer $(1997 ; 2000 ; 2010)$ and Kupfer et al. $(2017 ; 2018)$ for approximately twenty years. This research aimed to indicate the resources of Therapeutic Education for the treatment of ASD through school inclusion; also ponting out some of its theoretical foundations. As for the methodology, it was a specific literature review, qualitative approach and exploratory nature. Therapeutic Education seeks to enhance the possibilities of children, often restricted due to their psychic condition. In this context, Therapeutic Education can be defined as a set of practices that combine education and treatment for children with disabilities and/or severe developmental disorders, compromised in their subjective constitution. It has been observed that in the last years several studies have shown the effectiveness that a formation of educators focused on the principles of therapeutic education contributes greatly to the treatment and reduction of signs and symptoms related to autism spectrum disorder.

Keywords: Psychology. Therapeutic Education. Autism. Inclusion. Schools.

\section{INTRODUÇÃO}

Desde que o autismo foi descrito, na década de 1940 por Leo Kanner (Kanner, 1943) como um transtorno específico, distinto da Esquizofrenia Infantil, sua prevalência tem aumentado consideravelmente, segundo a estimativa apresentada pela American Psychological Association através do Manual Diagnóstico e Estatístico de Transtornos Mentais, é de que "1\% da população" mundial de crianças e adultos apresenta o Transtorno (DSM-5, 2014, p. 55).

Hoje é um direito de toda e qualquer criança, independentemente de suas particularidades, estar integrada no sistema de ensino, sendo o Estado e a família devedores desse mesmo direito. De acordo com o art. 4ㅇ do Estatuto da Criança e do Adolescente (Lei $\mathrm{n}$. 8.069, de 13 de julho de 1990), considera-se "dever da família, da comunidade, da sociedade em geral e do Poder Público assegurar, com absoluta prioridade, a efetivação dos direitos referentes à vida, a saúde, à alimentação, à educação [...]".

Em se tratando do direito à educação das crianças com algum tipo de deficiência, de acordo com o art. 27 do Estatuto da Pessoa com Deficiência (Lei n.13.146, de 6 de julho de 2015) a "educação constitui direito da pessoa com deficiência, assegurados sistema educacional inclusivo em todos os níveis e aprendizado ao longo de toda a vida". Cabe ao poder público assegurar, criar, desenvolver, implementar, incentivar, acompanhar e avaliar o sistema educacional inclusivo, aprimorando os sistemas educacionais, o projeto pedagógico, a oferta e adoção de medidas individualizadas, formação e disponibilização de professores para $o$ atendimento educacional especializado, etc. 
É sabido que o sistema de ensino sofreu mutações no cenário mundial desde a década de 1960, período coincide com o da eclosão de movimentos sociais mais amplos, de expressão da liberdade humana em diversos pontos da vida: sexual, econômica, política, existencial, etc. Em se tratando da inclusão dos chamados deficientes no sistema de ensino regular, nos anos 1970 iniciou-se a reforma da educação especial, trazendo a modalidade de educação especial para dentro da escola regular. Este enfoque na admissão dos deficientes em escolas regulares (escolas que agora possuem suas classes especiais), mostrou-se um tanto quanto limitado e ainda excludente, por implicar na rotulação e na segregação de alunos "problemáticos", atuando de forma individualizada, sem modificar o sistema de ensino como um todo, o ambiente escolar e sua cultura. Por isso, desde aproximadamente os anos 1990 até hoje muito se fala em escolas inclusivas, supondo modificações estruturais no sistema de ensino, no currículo comum (currículo mais equilibrado e inclusivo), na cultura e no clima escolar, assim como intervenções terapêuticas mais globais e não excludentes. Nesse contexto surge o papel do educador terapêutico, a criança autista deve compartilhar, ao máximo possível, dos mesmos ambientes e recursos educativos que as demais crianças ditas normais, participando em igualdade da operação educativa, e para isso a escola deve também atender às suas necessidades subjetivas.

Essas mudanças têm incitado, até os dias atuais, os/as psicólogos/as a construírem meios eficazes para a inclusão dessas crianças, notadamente no que se tem chamado de Educação Terapêutica. Tal perspectiva de trabalho inclusivo com crianças autistas considera que a escola pode, juntamente com atendimentos realizados em clínicas especializadas, cumprir um papel notável no tratamento dos sintomas do TEA. Percebe-se assim, em conjuntura com a atual perspectiva da inclusão escolar, a necessidade de proporcionar à criança com autismo a possibilidade de circular de forma saudável e terapêutica em espaços de convivência com as crianças que estão inseridas no Ensino Regular. Nesse âmbito, a Educação Terapêutica pode ser definida como um conjunto de práticas que aliam educação e tratamento para crianças deficientes e/ou com graves distúrbios de desenvolvimento, comprometidas em sua constituição subjetiva.

Pode-se dizer que há três eixos em torno dos quais gira a Educação Terapêutica: a inclusão escolar, o eixo simbólico e a operação educativa propriamente dita. Mas como a integração em uma escola, ou, o que dá no mesmo, a circulação social, pode ser terapêutica? Pode-se responder a esta pergunta introduzindo a hipótese de que, ao dar à criança um lugar na escola, está sendo feita uma atribuição imaginária de lugar social, operando o reconhecimento subjetivo e intersubjetivo na construção da identidade. A formação de educadores e educadoras voltada aos princípios da educação terapêutica contribui sobremaneira para o tratamento e redução de sinais e sintomas atinentes ao transtorno no espectro autista. Os Educadores Terapêuticos são grandes auxiliares, pois têm as estratégias certas na socialização dessas e das demais crianças no ambiente escolar, não focando somente no indivíduo autista, como brincadeiras/ tarefas em grupo, atividades que promovam a participação de todos, o reconhecimento de si e do outro, criação de ambientes que permitam a permanência harmoniosa do estudante junto aos demais, uso de recursos simbólicos que estimulem a comunicação e a interação e socialização do indivíduo. 
A Educação Terapêutica tem sido uma estratégia cada vez mais utilizada na última década, visando a inclusão de crianças com necessidades especiais dentro do ensino regular. Tais estratégias vêm sendo desenvolvidas por Kupfer (1997; 2000; 2010) e Kupfer et al. (2017; 2018) há aproximadamente vinte anos. A referente pesquisa teve por objetivo indicar os recursos da Educação Terapêutica para o tratamento do TEA através da inclusão escolar, apontando também alguns dos seus fundamentos teóricos.

\section{MATERIAIS E MÉTODOS}

Este artigo resultou de uma pesquisa de literatura específica, onde foi delimitado como objeto de estudo a perspectiva da Educação Terapêutica e da inclusão escolar no tratamento do TEA. Trata-se de um estudo de natureza básica e exploratória, de abordagem qualitativa, realizado por um aluno de graduação, com apoio do Programa de Bolsas Universitárias do Estado de Santa Catarina - UNIEDU, juntamente com a Universidade do Contestado - Campus Rio Negrinho. Em orientações semanais foi apresentado o interesse do aluno de Psicologia pela temática do autismo e da inclusão escolar, sendo orientado a pesquisar a temática da Educação Terapêutica. Delimitou-se a partir dessa exploração inicial, que durou os primeiros meses do levantamento de literatura, a escolha por indicar, como objetivo principal, os recursos da Educação Terapêutica para a inclusão e o tratamento do TEA. O trabalho exigiu primeiramente um recuo, para compreender as bases teóricas da Educação Terapêutica e a teoria psicanalítica do autismo. A partir de então os critérios de inclusão foram delimitados para a coleta de dados: publicações atuais pertinentes a temática da educação terapêutica como recurso a inclusão escolar no tratamento do TEA; publicações sobre a orientação teórica que a fundamenta essa prática específica. O material sobre a parte propriamente teórica se mostrou escasso, motivo pelo qual alargamos o critério de inclusão para todos aqueles artigos que, mesmo não declaradamente de orientação psicanalítica, apresentassem uma revisão ou um posicionamento crítico frente as diversas teorias que explicam o autismo, dentre elas a psicanálise. Optamos por excluir todos os materiais que não tratassem exclusivamente da Educação Terapêutica na inclusão e tratamento do TEA ou que não fossem pertinentes por apontar, mesmo que indiretamente, suas bases teóricas e compreensão do autismo. Por fim, os dados foram sistematizados e apresentados em duas etapas nos resultados: os que indicam a teoria que subjaz a prática, e os que indicam os recursos que implicam essa prática. Os artigos foram coletados através do Portal de Periódicos da CAPES, enquanto que as pesquisas em nível de pós-graduação foram coletadas através da Plataforma Sucupira, que compila as defesas de mestrado e doutorado realizadas no país.

\section{RESULTADOS E DISCUSSÕES}

Em uma carta em que Jung escreveu a Freud, datada de 13 de maio de 1907 (Freud e Jung (1906-1914/1975), descobrimos como Bleuler (1908) cunhou o termo autismo. O mesmo se recusava a empregar o termo autoerotismo - forjado por Havelock Ellis (1898) e retomado por Freud, em “Três ensaios sobre a teoria da sexualidade” (1905/2005, v. VII, p. 164) 
- por considerar seu conteúdo muito sexual. Dessa maneira, subtraiu "eros" do termo, fazendo a contração de "aut" com "ismo", criando um neologismo - autismo - para designar a perda de contato do esquizofrênico com a realidade. Quatro anos mais tarde, Bleuler (1911/1996) colocou o autismo em série com outros três distúrbios típicos da esquizofrenia - distúrbios das associações e da afetividade e a ambivalência -, considerando o autismo como perda do contato com a realidade. Os esquizofrênicos mais gravemente atingidos, os que não têm mais contato com o mundo externo, vivem num mundo que lhes é próprio. Nessa evasão da realidade, acompanhada ao mesmo tempo pela predominância absoluta ou relativa da vida interior, encontra-se também o autismo (Bleuler in Kaufmann, 1996, p. 56). Trinta e dois anos se passaram até que, em 1943, nos Estados Unidos, o psiquiatra de origem austríaca, Leo Kanner, empenhou-se na construção de uma nova entidade nosográfica, uma síndrome clínica particular completa, que se distinguiria radicalmente da esquizofrenia de Bleuler: "distúrbios autísticos do contato afetivo", para designar os casos de retraimento em crianças menores de um ano de idade" (Ribeiro, Martinho \& Miranda, 2012, p.78)

A delimitação e estudo cientifico do autismo começaram com um extenso informe, publicado em 1943 por Leo Kanner. Em seu artigo intitulado "Alterações autistas do contato afetivo", Kanner descrevia com precisão e comentava de forma inteligente os casos de onze crianças que apresentavam um quadro de distúrbio do desenvolvimento caracterizado por: 1) Incapacidade para estabelecer relações com as pessoas, 2) um amplo conjunto de atrasos e alterações na aquisição e uso da linguagem 3) uma insistência obsessiva em manter o ambiente sem mudanças, acompanhada da tendência a repetir uma gama limitada de atividades ritualizadas. A partir dos anos 70, o autismo começou a ser compreendido como um "distúrbio profundo e global do desenvolvimento", ou seja, um transtorno evolutivo, ao invés de uma psicose semelhante a esquizofrenia adulta. Este enfoque é muito mais útil sob o ponto de vista educacional, e constitui um reflexo de um amplo conjunto de investigações em que se estabeleceu relações entre o desenvolvimento normal e o autista.

O Transtorno no Espectro Autista (TEA), como é chamado hoje, é considerado um Transtorno Global do Desenvolvimento, ou seja, sua etiologia compreende a união entre fatores inatos e ambientais, genéticos e vivenciado particularmente, incluindo fatores relacionais, sempre em uma experiência de vida singular. Seus sinais e sintomas começam a se destacar desde os primeiros anos de vida da criança e interferem significativamente nas aquisições psíquicas. Segundo a quinta edição do Manual Diagnóstico e Estatístico dos Transtornos Mentais (DSM-5, 2014), o primeiro critério diagnóstico do transtorno refere-se a "déficits persistentes na comunicação social e na interação social em múltiplos contextos" (DSM-5, 2004 , p. 50). O DSM cita ainda outros aspectos do transtorno, como padrões restritivos e repetitivos no comportamento e na expressão de interesses do indivíduo, e indica que "o estágio em que o prejuízo funcional fica evidente irá variar de acordo com as características do indivíduo e seu ambiente" (DSM-5, 2004, p. 53).

Desde que foi cunhado, o termo diagnóstico autismo foi sofrendo suas mutações, pois novos indivíduos autistas surgiram, muitas vezes com predomínio em uma ou outra característica do transtorno, com ou sem prejuízos intelectuais, alargando sua compreensão. 
Até hoje não existe propriamente um consenso nem uma certeza quanto a sua causalidade, mas os critérios diagnósticos do DSM-5 parecem ser um campo comum para iniciar alguma comunicação científica. Os sintomas de autismo não se manifestam por igual, nem tem o mesmo significado em diferentes fases da vida, mas são relativamente os mesmos indicados no manual: estereotipias, grave isolamento e prejuízo na comunicação social. Naturalmente podem existir diversas co-morbidades associadas, diferenças relacionas ao QI, ao nível linguístico e simbólico, ao temperamento, e a gravidade dos sintomas.

A pergunta que a ciência se faz é: como se origina o autismo? A resposta a essa questão etiológica sempre se dá no sentido de permitir pensar em uma proposta de tratamento. Seguiremos agora apresentando alguns fundamentos teóricos importantes para a educação terapêutica, que extraímos da discussão dos autores a respeito das teorias que explicam a etiologia do transtorno, em especial daquelas de base psicanalítica. Entre as publicações analisadas neste artigo, três explicam a causa dos TEA por fatores psicogênicos e relacionais (Kupfer \& Pechberty, 2010; Lima, 2010; Marfinati \& Abrão, 2014). Segundo Marfinati e Abrão (2014), a etiologia do autismo é proveniente de uma deficiência na constituição do ego, que consiste numa interrupção no desenvolvimento do sujeito devido a uma adaptação falha às suas necessidades, obrigando-o a reagir de forma a se fechar para as experiências externas, percebidas como invasivas, perdendo o sentido de self adquirido até então.

Kupfer e Pechberty (2010) enquadram o autismo como um problema psíquico e indicam a necessária hipótese do inconsciente colocada pela psicanálise. Neste sentido, apontam para o fato lastimável de que acabou por se difundir a crença de que a psicanálise culpa os pais, resultando em uma pesada crítica nas décadas de 40 e 50 do século XX. Corroborando com os autores, em nosso ponto de vista, pensamos se tratar de um grave equívoco (aliás, com claras intenções inconscientes) supor que a psicanálise "culpa" os pais. Ela, a psicanálise ${ }^{4}$, reconhece, isto sim, a responsabilidade de cada um para com o outro, a dimensão relacional e ética que a ciência muitas vezes buscou erradicar de si. Entende os problemas psíquicos e emocionais também sob o ponto de vista do reconhecimento intersubjetivo e dos afetos que as pessoas causam umas às outras, ao invés de reduzir o problema ao corpo individual e suas redes sinápticas ${ }^{5}$. Tal equívoco que se sustenta em uma visão individualista gestada no ocidente, que compreende que somos indivíduos (indivisíveis e independentes do outro) e últimos agentes causais.

Reconhecer a dimensão de alteridade na constituição do Eu - um Eu que é também o resultado das interações sociais - é, pensamos, ponto de partida, urgente para a inclusão e para

${ }^{4}$ É preciso tomar cuidado com generalizações do tipo "a psicanálise", pois tendem a ocultar as diferenças significantes entre as diversas teorias como a de Freud, Lacan, Winnicott, entre outros. Aqui nos permitimos ao uso do termo genérico simplesmente por que consideramos ser um lugar comum entre as diversas teorias psicanalíticas a valorização da dimensão do outro e do cuidado.

5 Se é verdade que Lacan excluiu a biologia de suas considerações teóricas, aderindo a outras matrizes epistêmicas como o estruturalismo e a linguística, afirmando que o inconsciente se estrutura como linguagem, isto é, na trama sociossimbóloca e familiar, o mesmo não vale para Freud, para quem não existia problema em considerar fatores genéticos, neurobiológicos e relacionais em suas equações etiológicas. 
compreender o desenvolvimento do autismo, e como será mostrado depois é de fato um dos fundamentos da Educação Terapêutica. Neste sentido, Lima (2010) evidencia que o autismo é resultante de falhas na instalação da pulsão no sujeito, ou seja, durante o processo de constituição do psiquismo do bebê é preciso realizar e fortalecer a sua experiência de presentificar-se no mundo. Quando esse processo não ocorre de maneira adequada e as necessidades do bebê (cuidado, acolhimento, espelhamento, significação, apresentação, condução, entre outros) não são supridas, podem surgir cisões na interação mãe-bebê nos primórdios de sua vida psíquica, ocorrendo uma interrupção do processo de amadurecimento da criança. Isso pode ser percebido através do isolamento, incomunicabilidade, hipersensibilidade sensorial, pobreza dos processos simbólicos e pela aparente "desconexão" entre a criança frente ao outro e aos objetos, que ocorre devido ao fato de estar tomada por intensas sensações que ficam concentradas em seus processos corporais.

Outros artigos elaboram reflexões críticas às causas dos TEA articuladas a fatores biológicos, inatos, hereditários e/ou sua relação com o ambiente (interação), na perspectiva psiquiátrica ou interdisciplinar (Freire \& Moraes, 2011; Januário \& Tafuri, 2009; Macedo, 2010; Pavone \& Rafaeli, 2011; Thomas, 2013) e, apesar de não apresentarem uma ideia concreta de etiologia, demarcam-na historicamente, diferenciando as primeiras investigações psicanalíticas que aproximavam a causa do autismo aos distúrbios do apego ou na causalidade biológica/orgânica. Nessa perspectiva, Macedo (2010) apresenta duas principais correntes etiológicas que se opõem: uma de origem orgânica e outra psicogênica. Para a primeira, a causalidade do autismo é considerada de natureza endógena ou inerente ao organismo e para a corrente psicogênica a causa está vinculada ao não estabelecimento de uma demanda adequada do bebê em relação à mãe (e depois, por extensão, à todo meio social em relação ao indivíduo autista), por falta de recursos de um ou de outro, acarretando perturbação na dialética comunicacional, o que levaria à "desistência" da relação entre ambos.

Freire e Moraes (2011), destacando os estudos vinculados a um ideal científico, como a neurociência, a partir da teoria dos "neurônios espelhos" como a causa do autismo, pois, segundo essa perspectiva teórica, os neurônios seriam ativados ao realizar uma ação ou ao observar outro da mesma espécie realizar essa mesma ação, promovendo um espelhamento do neurônio. Desse modo o neurônio passaria a simular automaticamente essa ação no cérebro, como se o observador estivesse de fato agindo (Freire \& Moraes, 2011). Dessa "função de espelhamento" da espécie, Lacan, de forma sucinta, delineou dois pontos de direção clínica: 0 primeiro, que indica que o autista já é um sujeito, mesmo que rechace a presença do Outro; e o segundo, que considera que o autista está, de forma muito singular, no campo do verbo e da linguagem, mesmo que refute a fala e o discurso.

Pavone e Rafaeli (2011) tecem críticas sobre as teorias que, tendo em vista que a manifestação dos sintomas é muito precoce, apontam a causalidade ao biológico, mas também abordam as teorias relacionais, ou a correlação entre ambas. Destacam que "para a psicanálise o plano da causalidade é outro, distinto das predisposições inatas do sujeito e de suas relações com as características do meio ambiente, nem se trata tampouco do plano da interação entre 
elas" (Pavone \& Rafaeli, p. 35). Nessa concepção ${ }^{6}$, segundo entendemos, os sujeitos não respondem da mesma forma a um determinado estímulo. Estritamente, não há sujeito, tampouco estímulos. O Eu é um Outro. Recusa-se a mente, aonde o comportamento seria decorrente da interpretação, entrada e saída, dos estímulos, conforme esquemas prévios e/ ou inatos ou então aprendidos por um todo e poderoso $\mathrm{Eu}$. O que há é linguagem, mas não como estímulo a ser interpretado, como um dado ou propriedade de um sujeito que fala, mas como uma relação afetiva originária antes de qualquer divisão entre interno e externo, relação direta e imediata de reconhecimento ou alienação. Essa relação sempre imediata e real (mas inconsciente) com a alteridade é que nos deixa marcas afetivas e nos torna radicalmente outro que o corpo biológico, e é só assim que podemos dizer que algo outro, inconsciente, "fala" através do nosso corpo. O Eu, portanto, se constitui desde processos de identificação em relações sociais. Por isso, uma falha na relação não funcionaria no esquema de causa-efeito, estímulo-resposta, mas antes dela, conforme uma lógica de reconhecimento ou mortificação do Eu, como jogo de poder anterior a qualquer discurso ou decodificação do discurso pelo sujeito.

Januário e Tafuri (2009) chamam a atenção para a transformação conceitual do autismo desde as descrições de Bleuler em 1911 e Kanner em 1956, para as definições relativas a déficits sensoriais de caráter crônico e incurável, sob uma perspectiva biologizante. Referem que Fédida em 1991 afirmava que tais conceituações se mostram limitadas, pois permanecem fixadas a etiologias genéticas ou neurobiológicas, que não dialogam com intervenções psicológicas ou psicanalíticas. Entre os demais artigos que abordam as causas dos TEA, algumas publicações referem-se à perspectiva multicausal e transdisciplinar, que nos parece ser mais razoável, ou seja, a partir de um conjunto de aspectos constitucionais, biológicos, genéticos, ambientais, psíquicos e relacionais que devem “coabitar” num sujeito singular e de modo singular, e compreender que se referem de formas distintas ao mesmo objeto (Carvalho, 2011; Cullere-Crespin, 2010; Fonseca, 2012; Serra, 2010; Wajntal, 2013).

Fonseca (2012) ressalta que entre os aspectos ambientais e a sua relação com a gênese dos TEA, os fatores ligados à cultura ou às rápidas mudanças nas práticas parentais dos centros urbanos têm sido negligenciados nas publicações atuais. Desse modo, os aspectos biológicos e os ambientais não diferem a princípio, mas as influências de um ou de outro podem ser difíceis ou fáceis de reverter. Ou seja, as suscetibilidades inatas como a falta de algum dispositivo neurobiológico ou a presença de um transtorno neuronal favoreceriam, alinhados a outras condições, a ocorrência dos TEA (Carvalho, 2011). A aproximação da psicanálise e das teorias sociogenéticas, segundo Carvalho (2011), compreende que alguns aspectos do funcionamento psíquico já estão presentes nos indivíduos desde o seu nascimento, pois são características que constituem o ser humano ontogeneticamente, tais como o fator "instinto" (Freud já insistia nessa tese). Para essa linha teórica, esse fator está na raiz das interações

${ }^{6}$ Compreendemos que implicitamente o autor se refere à psicanálise desde uma perspectiva lacaniana, que propositalmente exclui a biologia de sua formulação etiológica dos distúrbios mentais, não se atendo, por exemplo, a formulação etiológica que Freud apresenta, esta sim bastante próxima ao pensamento neurológico, interligando fatores genéticos/inatos e ambientais. 
sociais, ou seja, existe uma predisposição específica no bebê em relação ao outro da espécie para assegurar a possibilidade de mediação social, de reconhecimento e de comunicação ambas as funções primitivas da linguagem.

Wajntal (2013) e Cullere-Crespin (2010) evidenciam que o autismo é resultante de falhas na instalação da pulsão no sujeito. Do ponto de vista psicanalítico, esse fenômeno consiste na não instauração de determinadas estruturas psíquicas que propiciam ao sujeito condições de desenvolvimento normal e, portanto, sua ausência poderia acarretar déficits cognitivos, entre outros.

Em síntese, a maior parte dos autores considera que o TEA seja multicausal, que este é um fenômeno que exige múltiplas fundamentações teóricas, assim como múltiplas formas de terapêutica. A compreensão multicausal dos TEA sustenta-se nas similaridades comportamentais, o que causa estranhamento ao pensar a etiologia apenas como resultado de fatores ambientais desencadeantes ou contribuintes, tendo em vista os mais diversos contextos onde os TEA estão presentes. Serra (2010) relata que a compreensão etiológica por meio da neurociência e da teoria psicanalítica indica que existe um componente biológico que só pode se expressar ao atravessar o campo psíquico do sujeito e que apenas nas interações com o outro e com o meio é que estas falhas vão se exprimir e se retroalimentar.

No caso da educação terapêutica, como mencionamos acima, a dimensão psicogênica e relacional é de fundamental importância. A ideia de uma constituição do sujeito mediante o vínculo social, ou do autismo como o resultado de uma falha muito precoce nesse vínculo, como aborda a psicanálise, é tomada como base para a proposta terapêutica que mostraremos adiante.

\section{EDUCAÇÃO TERAPÊUTICA}

A Educação Terapêutica tem sido uma estratégia cada vez mais utilizada na última década, visando a inclusão de crianças com necessidades especiais dentro do ensino regular. Seus fundamentos teóricos derivam principalmente da psicanálise, de uma compreensão subjetiva e intersubjetiva do sofrimento psíquico da criança, que tentamos mostrar acima. Por isso, lhe importa sobretudo as trocas e interações no espaço escolar, a construção de uma identidade de si e do outro, de uma "ponte" entre o biológico da pulsão e o simbólico como presentificação no mundo e constituição de um sujeito. Trabalhos como o de Armiliato (2013), voltados para a educação infantil, vêm mostrando a eficácia da formação de educadores e educadoras voltada aos princípios da educação terapêutica para o tratamento e redução de sinais e sintomas atinentes ao transtorno no espectro autista.

Tais estratégias vêm sendo desenvolvidas por Kupfer $(1997 ; 2000 ; 2010)$ e Kupfer et al. $(2017 ; 2018)$ há aproximadamente vinte anos, que adere a uma abordagem psicanalítica. Desde então, a autora vem publicando diversos trabalhos sobre o tema, especialmente no âmbito do autismo e de outros transtornos invasivos do desenvolvimento e assim almejando possibilidades de construir estratégias tanto inclusivas quanto terapêuticas para o autismo dentro das instituições do Ensino Regular. Na Educação Terapêutica procura-se potencializar 
as possibilidades da criança, sempre com referência ao campo do outro e da circulação social, que perpassam o registro simbólico e a inserção no campo da linguagem e dos afetos. Nesse âmbito, a Educação Terapêutica pode ser definida como

[...] um conjunto de práticas que aliam educação e tratamento para crianças com graves distúrbios de desenvolvimento, ou se quiserem, crianças cuja posição na rede da linguagem, cuja inscrição no registro simbólico apresentam falhas ao ponto de ficar comprometida a sua constituição subjetiva, sua relação com o outro e sua circulação no campo social: psicóticas, autistas, sindrômicas, ou algumas portadoras de deficiências para quem tais falhas simbólicas acabam por se instalar (Kupfer, 1997, p. 57).

Para que a Educação Terapêutica opere como um instrumento facilitador da inclusão é preciso construir meios para capacitar os/as educadores/as que atuam cotidianamente junto às crianças. Conforme Mariotto (2009), desde a Educação Infantil, as crianças têm passado a maior parte de seu cotidiano junto a cuidadores em ambientes institucionais, como as creches e os centros de educação infantil. O que implica, segundo a autora, construir ferramentas não só de intervenção como de capacitação dessas crianças (Mariotto, 2009, p. 37). Enquanto diretrizes para a formação dos educadores, Mariotto e Bernardino indicaram que "uma formação sólida" destes profissionais deveria incluir conhecimentos sobre a constituição do sujeito e discussões constantes de seu trabalho através da criação de lugares de escuta no ambiente escolar (2009, p. 2628). A educação terapêutica é então um conjunto de práticas do qual o grupo de professores é parte integrante.

Considerações apresentadas no DSM-5, evidenciam como o ambiente no qual está inserida a criança interfere na manifestação de seus sintomas. Considerando a Política Nacional de Educação Especial (2008, p. 14), a qual preconiza a inclusão dos alunos com transtornos globais do desenvolvimento no Ensino Regular, nota-se como os profissionais da educação regular devem atentar também para as especificidades das crianças incluídas no sistema. Algo que se soma ao que a Lei n. 12.764/2012, que institui a Política Nacional dos Direitos da Pessoa com Transtorno no Espectro Autista, notadamente quando esta indica que "a pessoa com transtorno do espectro autista incluída nas classes comuns de ensino regular [...] terá direito a acompanhante especializado".

Pode-se dizer que há três eixos em torno dos quais gira a Educação Terapêutica: a inclusão escolar, o eixo simbólico e a operação educativa propriamente dita. Entende-se que a ideia de escola enquanto um lugar social aparece como zona intermediária entre o espaço público e privado, coletivo e individual. A ordem objetiva que transcende os indivíduos determina as normas de conduta e ação, e a operação educativa consiste, em parte, em informar os indivíduos quanto aos códigos e regras de convivência. A construção da identidade segue um movimento dialético que depende essencialmente do reconhecimento dessa ordem objetiva compartilhada, que se opõe à identidade como alteridade. Não há reconhecimento de si ou sujeito enquanto não houver reconhecimento daquilo que é exterior ao Eu, enquanto não se instala um certo princípio de realidade. O jogo, ou eixo simbólico, é justamente a mediação entre os desejos individuais e o espaço coletivo, que é central para a Educação Terapêutica. 
Ainda no âmbito dos recursos à educação terapêutica, o instrumento APEGI Acompanhamento Psicanalítico de Crianças em Instituições, Escolas e Grupos, foi elaborado por Kupfer e Bernardino para observar a constituição do sujeito a partir dos três anos de idade. Não é um instrumento de avaliação diagnóstica, mas sim para se observar fenômenos do desenvolvimento e as relações sociais em sala de aula (Kupefer, Bernardino \& Mariotto, 2014).

A intervenção precoce, desde essa base psicanalítica do APEGI, visa o processo do desenvolvimento das crianças, mas atinge principalmente a dimensão dos afetos e da convivência social, do reconhecimento de si e do espaço objetivamente compartilhado. Dessa forma, realizar intervenções dentro das escolas, que não apenas focalizem na criança, mas também o campo dos afetos e das relações, desde o início do diagnóstico, pode-se ter melhores resultados no desenvolvimento destas. Entende-se que os comportamentos podem ser modificados com a intervenção precoce. Com relação às crianças com TEA, a intervenção precoce tem um melhor resultado nas áreas de comunicação e também nas habilidades sociais (Bosa, 2006).

No APEGI, são utilizados os seguintes eixos amarrados pela teoria, observação e prática, que norteiam o olhar do educador terapêutico: o brincar e a fantasia, o corpo e sua imagem, manifestação diante das normas, posição frente à lei, a fala e a posição na linguagem, presença/ reconhecimento de sujeito e função do semelhante (Kupfer et al., 2009). A estrutura do APEGI é a de um roteiro orientador para a condução de quatro consultas ou entrevistas que focalizam não apenas na criança e em seus atributos individuais, mas em como ocorrem as relações afetivas nos ambientes familiar e escolar. Uma entrevista é realizado com os pais e criança; uma com a criança individualmente; outra com a professora da criança e a quarta com a criança em grupo. A intervenção que se segue a partir desse instrumento, elaborado desde uma matriz psicanalítica, leva em conta a capacitação dos professores e do grupo em sala de aula. O roteiro para a condução do instrumento segue no Quadro 1.

Quadro 1

\section{Roteiro de condução do instrumento APEGI}

\begin{tabular}{|l|l|l|l|l|l|}
\hline Eixos & \multicolumn{1}{|c|}{ Roteiro } & Sim & Há esboço & Não & Justificativa \\
\hline \multirow{2}{*}{ P/R S } & Há reconhecimento de sujeito? & & & & \\
\cline { 2 - 6 } & Há presença de sujeito? & & & & \\
\hline BF & Há um brincar constituído? & & & & \\
\hline CI & $\begin{array}{l}\text { A imagem corporal está } \\
\text { constituída? }\end{array}$ & & & & \\
\hline FL & $\begin{array}{l}\text { A criança está inserida na fala e na } \\
\text { linguagem? }\end{array}$ & & & & \\
\hline FP & Há operação da função paterna? & & & & \\
\hline FS & $\begin{array}{l}\text { A relação com o semelhante está } \\
\text { constituída? }\end{array}$ & & & & \\
\hline
\end{tabular}

Fonte: Elaborado com base em "Acompanhamento psicanalítico de crianças em escolas, grupos e instituições (APEGI): primeiros resultados”, de M. C. M. Kupfer, L. M. F. Bernardino, M. E. \& Pesaro. Estilos da Clínica, 2018. 


\section{CONSIDERAÇÕES FINAIS}

Houve um longo período de exclusão dos ditos anormais nas escolas, hoje falamos em escolas inclusivas, em educação para todos, graças às lutas sociais por maior liberdade.

O Transtorno no Espectro Autista (TEA), como é chamado hoje, é considerado um Transtorno Global do Desenvolvimento, ou seja, sua etiologia compreende a união entre diversos fatores. Seus sinais e sintomas começam a se destacar desde os primeiros anos de vida da criança e interferem significativamente nas aquisições psíquicas. Como mostramos, existem diversas teorias sobre o desenvolvimento do TEA, onde trazem um certo meio termo mais razoável, aonde fala-se em múltiplas causas, entre teorias psiquiátricas, neurobiológicas e psicanalíticas, existindo também fatores sociais (inclui-se aqui o que a psicanálise trata como linguagem e campo dos afetos) que contribuem para o desenvolvimento.

Nos dias de hoje, a Educação Terapêutica tem sido uma estratégia cada vez mais utilizada, visando a inclusão e o desenvolvimento de crianças com necessidades especiais dentro do ensino regular. Dentro do contexto atual das políticas de inclusão, a Educação Terapêutica indica para um avanço, entre outros, no quesito de não rotular o aluno, pois pretende uma intervenção mais global, que atinge principalmente a escola e os professores, os modos de relações em sala de aula, não isolando a criança. Para que ela opere como um instrumento facilitador da inclusão é preciso construir meios para capacitar os/as educadores/as que atuam cotidianamente junto às crianças. Enquanto diretrizes para a formação dos educadores, Mariotto e Bernardino indicaram que "uma formação sólida" destes profissionais deveria incluir conhecimentos sobre a constituição do sujeito e discussões constantes de seu trabalho através da criação de lugares de escuta no ambiente escolar. (2009, p. 2628). A educação terapêutica é então um conjunto de práticas do qual o grupo de professores é parte integrante, um tipo de intervenção que promove intervenções nas relações professor-aluno e aluno-aluno.

Atualmente, o instrumento APEGI - Acompanhamento Psicanalítico de Crianças em Instituições, Escolas e Grupos, o qual foi elaborado por Kupfer e Bernardino para observar a constituição do sujeito a partir dos três anos de idade, serve de grande ajuda para guiar a Educação Terapêutica e a estimulação precoce das crianças com TEA (Kupefer \& Bernardino; Mariotto, 2014).

Acredita-se que esta pesquisa de natureza exploratória possa servir como o início de um trabalho mais extenso, que incidirá positivamente em intervenções práticas junto aos professores do Ensino Regular. Espera-se que a revisão de literatura auxilie os estudantes de psicologia a estabelecerem sequências estratégias interventivas dentro do paradigma da Educação Terapêutica. Espera-se, sobretudo, que os profissionais do Ensino Regular (educadores/as, gestores/as, psicólogos/as escolares) possam fortalecer suas práticas através de um olhar crítico, amadurecido e que considere as vicissitudes da inclusão e da formação de professores. 


\section{REFERÊNCIAS}

Armiliato, V. (2013). A Metodologia IRDI: detecção precoce de risco psíquico por educadoras de creche de Curitiba através de acompanhamento em serviço e supervisão. In XI Congresso Nacional de Educação - EDUCERE: Formação docente e sustentabilidade: um olhar transdisciplinar. Curitiba: Champagnat.

DSM-5. (2014). Manual Diagnóstico e Estatístico de Transtornos Mentais (5a ed.). Porto Alegre: Artmed.

Camisão, I. F. F. (2004). Percepção dos professores do ensino básico acerca da inclusão educativa de alunos com necessidades especiais (Dissertação de mestrado). Universidade do Minho, Instituto de Educação e Psicologia, Braga, Portugal.

Fragoso, F., \& Casal, J. (2012). Representações sociais dos educadores de infância e a inclusão de alunos com necessidades educativas especiais. Revista Brasileira de Educação Especial, 18(3), 527-546.

Kanner, L. (1943). Autistic Disturbances of affective contact. Nervous Child, 2(1), 217-250.

Kupfer, M. C. M. (1997). Educação Terapêutica: o que a psicanálise pode pedir à educação. Estilos da Clínica, 2(2), 53-61.

Kupfer, M. C. M. (2000). Educação para o futuro: psicanálise e educação. São Paulo: Escuta.

Kupfer, M. C. M. (2010). O sujeito na psicanálise e na educação: bases para a educação terapêutica. Educação e Realidade, 35(1), 265-281.

Kupfer, M. C. M., Bernardino, L. M. F., \& Pesaro, M. E. (2018). Validação do instrumento "Acompanhamento psicanalítico de crianças em escolas, grupos e instituições" (APEGI): primeiros resultados. Estilos da Clínica, 23(3), 558-573.

Kupfer, M. C., Bernardino, L. M., \& Yamashita, A. G. G. (2018). A Educação Terapêutica no trabalho com pais de bebês e crianças pequenas na Educação Infantil em tempos de autismo. Aprender, 11(17), 111-122.

Kupfer, M. C. M., Patto, M. H. S., \& Voltolini, R. (Orgs.). (2017). Práticas inclusivas em escolas transformadoras: acolhendo o aluno-sujeito. São Paulo: Escuta.

Lei n. 8.069, de 13 de julho de 1990. Dispõe sobre o Estatuto da Criança e do Adolescente e dá outras providências. Recuperado de http://www.planalto.gov.br/ccivil_03/leis//8069.htm

Lei n. 12.764, de 27 de dezembro de 2012. Institui a Política Nacional de Proteção dos Direitos da Pessoa com Transtornos do Espectro Autista; e altera o $\S 3^{\circ}$ do art. 98 da Lei $\mathrm{n}^{\circ}$ 8.112, de 11 de dezembro de 1990. Recuperado de http://www.planalto.gov.br/ ccivil_03/_ato2011-2014/2012/lei/l12764.htm

Lei n. 13.146, de julho de 2015. Institui a Lei Brasileira de Inclusão da Pessoa com Deficiência (Estatuto da Pessoa com Deficiência). Recuperado de http://www.planalto.gov.br/ ccivil_03/_ato2015-2018/2015/lei/l13146.htm

Mariotto, R. M. M. (2009). Cuidar, Educar e Prevenir: as funções da creche na subjetivação dos bebês. São Paulo: Escuta. 
Mariotto, R. M. M., \& Bernardino, L. M. F. (2009). Detecção de riscos psíquicos em bebês de berçários de Centros Municipais de Educação Infantil de Curitiba. In IX Congresso Nacional de Educação, 9, Encontro Sul Brasileiro de Psicopedagogia. Curitiba: PUCPR.

Política Nacional de Educação Especial na perspectiva da Educação Inclusiva (2008). Brasília: MEC/SEESP.

Ribeiro, M. A. C., Martinho, M. H., \& Miranda, E. R. (2012). O sujeito autista e seus objetos. A peste, 4(2), 77-89.

Vitta, F. C. F. de, Vitta, A. de, \& Monteiro, A. S. R. (2010). Percepção de professores de educação infantil sobre a inclusão da criança com deficiência. Revista Brasileira de Educação Especial, 16(3), 415-428.

Recebido em: 20-02-2020

Primeira decisão editorial: $14-05-2020$

Aceito em: 04-06-2020 